\title{
x
}

\section{Memory Characteristics of Pt Nanoparticle-embedded MOS Capacitors Fabricated at Room Temperature}

\author{
Sungsu Kim, Kyoungah $\mathrm{Cho}^{\dagger}$, Kiyeol Kwak, and Sangsig Kim ${ }^{\dagger}$ \\ Department of Electrical Engineering, Korea University, Seoul 136-713, Korea
}

Received April 20, 2012; Revised May 29, 2012; Accepted May 29, 2012

\begin{abstract}
In this study, we fabricate Pt nanoparticle (NP)-embedded MOS capacitors at room temperature and investigate their memory characteristics. The Pt NPs are separated from each other and situated between the tunnel and control oxide layers. The average size and density of the Pt NPs are $4 \mathrm{~nm}$ and $3.2 \times 10^{12} \mathrm{~cm}^{-2}$, respectively. Counterclockwise hysteresis with a width of $3.3 \mathrm{~V}$ is observed in the high-frequency capacitance-voltage curve of the Pt NP-embedded MOS capacitor. Moreover, more than $93 \%$ of the charge remains even after $10^{4} \mathrm{~s}$.
\end{abstract}

Keywords: Memory, Nanoparticle, Pt, Sputter

\section{INTRODUCTION}

Recently, the fabrication of nonvolatile memory devices using room-temperature processing has attracted substantial attention, since plastic-based devices, as one of the promising nextgeneration devices, are vulnerable to heat [1-7]. Among the various nonvolatile memory devices, a nano-floating gate memory (NFGM) structure containing nanoparticles (NPs) embedded in gate layers has been considered as a strong candidate for nextgeneration nonvolatile memory devices, owing to the reliability of its charge retention and endurance [8-10]. In particular, metal NPs with a high work-function have been actively utilized for high performance NFGM devices, since they play a role in efficient charge storage with good retention properties [11-13]. Up to now, NFGM devices composed of metal NPs with a high workfunction have been made by solution-processable fabrication at room temperature [14]. Nevertheless, solution-processable fabrication has difficulties in terms of its reproducibility and imposes limits on the fabrication of 3-dimensioinal structures such as nanowire-based TFTs or FinFETs. Therefore, in this study, we propose a new procedure for the room temperature fabrication

${ }^{\dagger}$ Author to whom all correspondence should be addressed:

E-mail: chochem@korea.ac.kr, sangsig@korea.ac.kr

Copyright $@ 2012$ KIEEME. All rights reserved.

This is an open-access article distributed under the terms of the Creative Commons Atribution Non-Commercial
License (httr:///creativecommons.org /icenses by-nc/3.0) which permits unrestricted noncommercial use, Llicnse
distribution, and reproduction in any medium, provided the original work is property cited. of NFGM devices utilizing platinum (Pt) NPs prepared in a sputtering system with a cooling unit. Pt with a work-function of 5.65 $\mathrm{eV}$ is a representative metal with a relatively high work-function.

\section{EXPERIMENTS}

Silicon (p-type, ( $\left.\begin{array}{lll}1 & 0 & 0\end{array}\right)$ orientation) wafers with 6.3-nm-thick thermally grown oxide layers were utilized as the substrates. Pt NPs were formed on the $\mathrm{SiO}_{2}$ layers used as the tunneling oxides by the DC magnetron sputtering method. A Pt target was sputtered for $10 \mathrm{~s}$ under Ar gas at a pressure of $3.0 \mathrm{mTorr}$ with a sputtering power of $25 \mathrm{~W}$. Then, control oxide layers of $\mathrm{SiO}_{2}$ with a thickness of $45 \mathrm{~nm}$ were deposited by the RF magnetron sputtering method under an $\mathrm{Ar}$ and $\mathrm{O}_{2}$ atmosphere. During all of the sputtering processes, the temperature of the substrates was maintained at $290 \mathrm{~K}$ with a water-cooling unit. Finally, top electrodes of Au were deposited on the control oxide layers by the thermal evaporation method. The structure and electrical characteristics of the devices were examined by high-resolution transmission electron microscopy (HR-TEM; Tecnai G2 F30) and a semiconductor parameter analyzer (HP 4285A), respectively.

\section{RESULTS AND DISCUSSION}

The HR-TEM image of the Pt NPs sputtered at room temperature is shown in Fig. 1, revealing a discrete morphology with an 


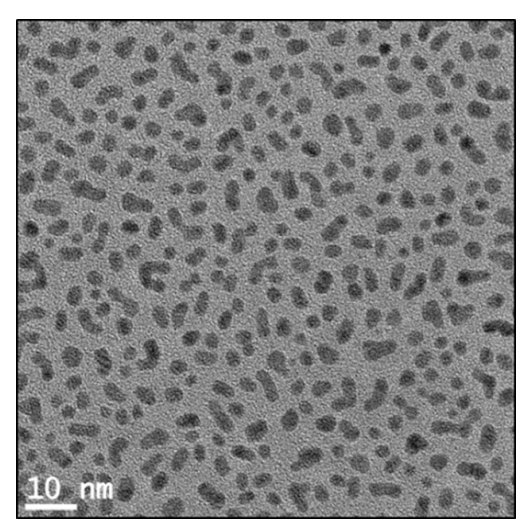

Fig. 1. HR-TEM image of Pt NPs sputtered on a $\mathrm{SiO}_{2}$ layer.

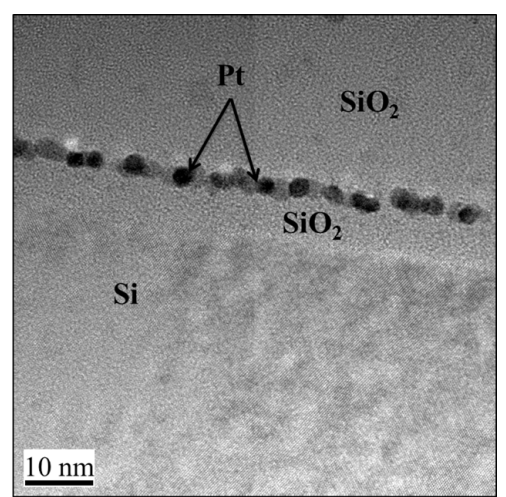

Fig. 2. Cross-sectional HR-TEM image of the Pt NP-embedded MOS capacitor.

average size of $4 \mathrm{~nm}$. The density of the Pt NPs estimated from the HR-TEM image is about $3.2 \times 10^{12} \mathrm{~cm}^{-2}$. The cross-sectional HR-TEM image shown in Fig. 2 clearly indicates that the Pt NPs are formed separately from each other and situated between the tunnel and control oxide layers.

The high-frequency capacitance-voltage (C-V) curves taken at a frequency of $1 \mathrm{MHz}$ with a sweep rate of $0.2 \mathrm{~V} / \mathrm{s}$ are plotted in Fig. 3. While the C-V curve of the MOS capacitor without any Pt NPs shows a negligible flat-band voltage shift when the gate voltage is swept from $10 \mathrm{~V}$ to $-10 \mathrm{~V}$, the $\mathrm{C}-\mathrm{V}$ curve obtained for the Pt NP-embedded MOS capacitor has a flat-band voltage shift of about $3.3 \mathrm{~V}$ in a counterclockwise direction. The significant flat-band voltage shift is due to the presence of the Pt NPs. The observation reveals that charge trapping in the Pt NPs embedded in our MOS capacitor occurs through the injection of electrons from the p-Si substrates into the Pt NPs. The amount of charge carriers stored in the Pt NPs can be estimated by the following relation:

$$
\Delta V_{F B}=\left(\frac{d}{\varepsilon_{0} \varepsilon_{\text {oxide }}}\right) \cdot Q_{t}
$$

where $\Delta V_{F B}$ is the value of the flat-band voltage shift (3.3 V), $d$ is the tunneling oxide thickness $(6.3 \mathrm{~nm}), Q_{t}$ is the trapped charge density, and $\varepsilon_{\text {oxide }}$ is the dielectric constant of the gate insulator (3.9) [15]. The amount of charge carriers stored in the Pt NPs is estimated to be $2.45 \times 10^{12} \mathrm{~cm}^{-2}$. Considering the density of the sputtered Pt NPs, the number of carriers stored in each of the Pt NPs is calculated to be 0.7 .

The charge retention characteristics of the Pt NP-embedded

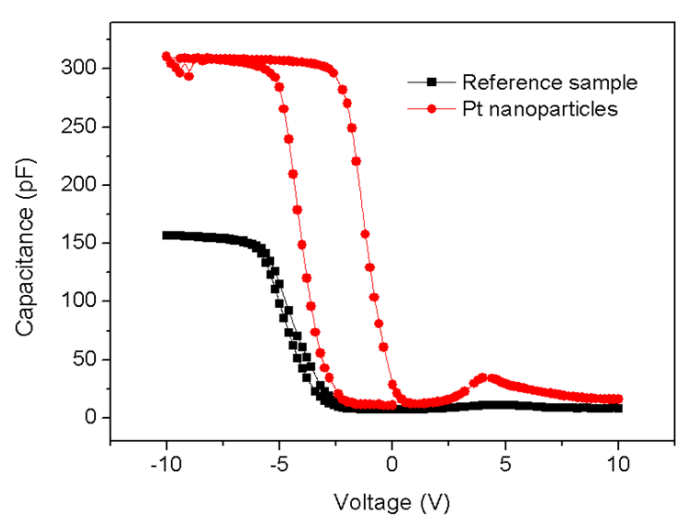

Fig. 3. The $\mathrm{C}-\mathrm{V}$ characteristics of the MOS capacitors without and with Pt NPs.

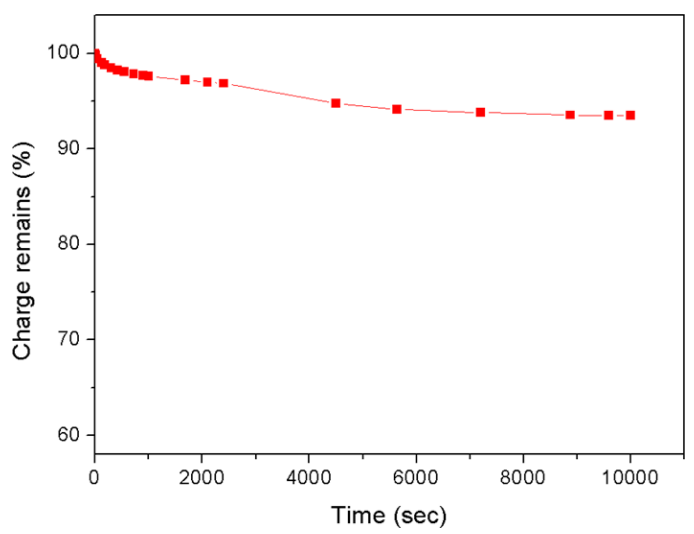

Fig. 4. Charge retention characteristics of the Pt NP-embedded MOS capacitor after applying a gate voltage stress of $-10 \mathrm{~V}$ for $1 \mathrm{~s}$.

MOS capacitor were examined through capacitance versus time (C-t) measurements. The Pt NP-embedded MOS capacitor was charged for $1 \mathrm{~s}$ at a bias voltage of $-10 \mathrm{~V}$, and the C-t measurement was then performed under a stress voltage of $-5 \mathrm{~V}$.

The remaining charge is defined as follows:

$$
\text { Remaining charge }(\%)=\left(\frac{C(t)-C_{F B}}{C(0)-C_{F B}}\right) \times 100
$$

where $C(t)$ and $C(0)$ are the capacitance at the measurement time and the initial capacitance, respectively. $\mathrm{C}_{\mathrm{FB}}$ is the flat-band capacitance during the forward bias sweeping. Figure 4 shows the excellent retention characteristics of our device, indicating that more than $93 \%$ of the charge remains even after $10^{4} \mathrm{~s}$.

\section{SUMMARY}

In this study, we fabricated Pt NP-embedded MOS capacitors using a sputtering system at room temperature. Pt NPs with a density of $3.2 \times 10^{12} \mathrm{~cm}^{-2}$ were formed separately from each other and situated between the tunnel and control oxide layers. The amount of the electrons stored in each of the Pt NPs was estimated to be 0.7 for the flat-band voltage shift of $\sim 3.3 \mathrm{~V}$ when the gate voltage was swept from 10 to $-10 \mathrm{~V}$. In addition, $93 \%$ of the charge remained even after $10^{4} \mathrm{~s}$, indicating good retention characteristics of the Pt NP-embedded MOS capacitor. 


\section{ACKNOWLEDGMENTS}

This work was supported by the Nano R\&D Program (M10703000980-08M0300-98010) and World Class University (WCU, R32-2008-000-10082-0) Project of the Ministry of Education, Science and Technology (Korea Science and Engineering Foundation).

\section{REFERENCES}

[1] Y. C. Yang, F. Pan, Q. Liu, M. Liu, and F. Zeng, Nano Lett. 9, 1636 (2009) [DOI: $10.1021 / \mathrm{nl} 900006 \mathrm{~g}$ ].

[2] E. Verrelli, D. Tsoukalas, K. Giannakopoulos, D. Kouvatsos, P. Normand, and D.E. Ioannou, Microelectron. Eng. 84, 1994 (2007) [DOI: 10.1016/j.mee.2007.04.078].

[3] J. Wu, S. Mao, Z. Ye, Z. Xie, and L. Zheng, J. Mater. Chem. 20, 6512 (2010) [DOI: 10.1039/C0JM00729C].

[4] S. Gopfert, L. Worschech, S. Lingemann, C. Schneider, D. Press, S. Hofling, and A. Forchel, Appl. Phys. Lett. 97, 222112 (2010) [DOI: 10.1063/1.3520522].

[5] I. Kang, Y. Kim, H. Seo, S. Son, E. Yoon, S. Joo, and C. Ahn, Appl. Phys. Lett. 98, 212102 (2011) [DOI: 10.1063/1.3593096].

[6] M. Lee, S. Kim, C. Lee, H. Yin, S. Ahn, B. Kang, K. Kim, J. Park,
C. Kim, I. Song, S. Kim, G. Stefanovich, J. Lee, S. Hung, Y. Kim, and Y. Park, Adv. Funct. Mater. 19, 1587 (2009) [DOI: 10.1002/ adfm.200801032].

[7] Y. Wang, Y. Huang, Y. Song, X. Zhang, Y. Ma, J. Liang, and Y. Chen, Nano Lett. 9, 220 (2009) [DOI: 10.1021/nl802810g].

[8] M. F. Hung, Y. C. Wu, and Z. Y. Tang, Appl. Phys. Lett. 98, 162108 (2011) [DOI: 10.1063/1.3582925].

[9] D. Gupta, M. Anand, S. W. Ryu, Y. K. Choi, and S. H. Yoo, Appl. Phys. Lett. 93, 224106 (2008) [DOI: 10.1063/1.3041777].

[10] S. J. Kim and J. S. Lee, Nano Lett. 10, 2884 (2010) [DOI: 10.1021/ nl1009662].

[11] P. K Singh, G. Bisht, R. Hofmann, K. Singh, N. Krishna, and S. Mahapatra, IEEE Electron Device Lett. 29, 1389 (2008) [DOI: 10.1109/LED.2008.2007308].

[12] S. P. Kim, T. H. Lee, D. U. Lee, E. K. Kim, H.-M. Koo, W.-J. Cho, and Y.-H. Kim Jpn. J. Appl. Phys. 47, 4996 (2008) [DOI: 10.1143/ JJAP.47.4996].

[13] Z. Liu, C. Lee, V. Narayanan, G. Pei, and E. C. Kan, IEEE Trans. Electron Devices 49, 1606 (2002) [DOI: 10.1109/ TED.2002.802617].

[14] T. Teranishi, M. Hosoe, T. Tanaka, and M. Miyake, J. Phys. Chem. B 103, 3818 (1999) [DOI: 10.1021/jp983478m].

[15] J. Binbin and S. Chihtang, J. Semicond. 32, 041001 (2011) [DOI: 10.1088/1674-4926/32/4/041001]. 